\title{
Characterization of beta-thalassemia mutations in patients from the state of Rio Grande do Norte, Brazil
}

\author{
Zama Messala Luna da Silveira ${ }^{1}$, Maria das Vitórias Barbosa ${ }^{1}$, \\ Thales Allyrio Araújo de Medeiros Fernandes ${ }^{2}$, Elza Miyuki Kimura ${ }^{3}$, Fernando Ferreira Costa ${ }^{4}$, \\ Maria de Fátima Sonati ${ }^{3}$, Ivanise Marina Moretti Rebecchi ${ }^{1}$ and Tereza Maria Dantas de Medeiros ${ }^{1}$ \\ ${ }^{1}$ Departamento de Análises Clínicas e Toxicológicas, Universidade Federal do Rio Grande do Norte, \\ Natal, RN, Brazil. \\ ${ }^{2}$ Departamento de Ciências Biomédicas, Universidade do Estado do Rio Grande do Norte, \\ Mossoró, RN, Brazil. \\ ${ }^{3}$ Departamento de Patologia Clínica, Faculdade de Ciências Médicas, \\ Universidade Estadual de Campinas, Campinas, SP, Brazil. \\ ${ }^{4}$ Hemocentro, Universidade Estadual de Campinas, Campinas, SP, Brazil.
}

\begin{abstract}
35 unrelated individuals were studied for characterization as either heterozygous or homozygous for beta-thalassemia. Molecular analysis was done by PCR/RFLP to detect the mutations most commonly associated with beta-thalassemia ( $\beta^{0}$ IVS-I-1, $\beta^{+}$IVS-I-6, and $\beta^{0} 39$ ). In the patients who showed none of these mutations, the beta-globin genes were sequenced. Of the 31 heterozygous patients, $13(41.9 \%)$ had the $\beta^{+}$IVS-I-6 mutation, 15 (48.4\%) the $\beta^{0}$ IVS-I-1 mutation, 2 (6.5\%) the $\beta^{+}$IVS-I-110 mutation and 1 (3.2\%) the $\beta^{+}$IVS-I-5 mutation. IVS-I-6 was detected in the four homozygotes. The mutation in codon 39, often found in previous studies in Brazil, was not detected in the present case. This is the first study aiming at identifying mutations that determine beta-thalassemia in the state of Rio Grande do Norte.
\end{abstract}

Key words: hereditary hemoglobinopathies, beta-thalassemia, mutations, PCR-RFLP, Brazilian population.

Received: November 30, 2010; Accepted: May 2, 2011.

Beta-thalassemia is a group of hemoglobin diseases caused by a reduction $\left(\beta^{+}\right.$thalassemia) or absence $\left(\beta^{0}\right.$ thalassemia) in the synthesis of beta-globin chains. More than 200 different types of mutations have been described as being responsible for this disease. Affected individuals can be heterozygous, compound heterozygous, or homozygous for beta-thalassemia, or even have interactions with other hemoglobinopathies. Their phenotypes include microcytic and hypochromic anemia, raised $\mathrm{HbA}_{2}$ levels, and various syndromes caused by the combination of $\beta^{0}$ and $\beta^{+}$alleles (Thein, 1998; Weatherall, 2001).

The frequency of heterozygotes in Brazil is around 1\% (Freitas and Rocha, 1983; Ramalho et al., 1999). Studies in the South and Southeast of Brazil have shown that the most frequent mutations are $\beta^{0} 39(\mathrm{C} \rightarrow \mathrm{T})$ and $\beta^{+}$ IVS-I-110 (G $\rightarrow$ A) (Martins et al., 1993; Reichert et al.,

Send correspondence to Tereza Maria Dantas de Medeiros. Departamento de Análises Clínicas e Toxicológicas, Universidade Federal do Rio Grande do Norte, Rua General Cordeiro de Farias $\mathrm{s} / \mathrm{n}, \quad 1^{\circ}$ andar, 59010-180 Natal, RN, Brazil. E-mail: tdantas@ufrnet.br.
2008), whereas in the Northeast, an entirely different pattern was observed, the most frequently encountered allele being $\beta^{+}$IVS-I-6 $(\mathrm{T} \rightarrow \mathrm{C})$, followed by $\beta^{0} \mathrm{IVS}-\mathrm{I}-1(\mathrm{G} \rightarrow \mathrm{A})$ (Araújo et al., 2003).

Due to the lack of information regarding the types of beta-thalassemia mutations encountered in the state of Rio Grande do Norte, an effort was made to characterize the disease in patients who were homozygous and heterozygous for beta-thalassemia, by way of hematological and molecular tests.

The sample consisted of 35 unrelated individuals (13 males and 22 females) with $\mathrm{HbA}_{2}$ levels above $3.5 \%$. Age was between 1 and 70 years and all were born in the state of Rio Grande do Norte. The subjects were recruited from individuals referred to the Integrated Laboratory Clinical Analysis, at Rio Grande do Norte Federal University, between April, 2008 and October, 2009, by hematologists from the public and private sectors for the diagnosis of possible anemia. The study was approved by the Research Ethics Committee of Rio Grande do Norte Federal University (CEP-UFRN, protocol number 015/08) in accordance with 
the standards laid down in the National Health Council resolution 196/96. All the participants or their legal guardians were informed of the aim of the study and signed a voluntary informed-consent form.

Samples of venous blood from each patient were collected in two sterile tubes, one with EDTA and the other without an anticoagulant. The aliquot of blood containing EDTA was used for measurement of red blood cell indices (ABX Diagnostics, Montpellier, France), alkaline hemoglobin electrophoresis (Dacie and Lewis, 1995), measurement of $\mathrm{HbA}_{2}$ by elution (Bezerra, 1984), quantification of $\mathrm{HbF}$ by alkaline denaturation (Betke et al., 1959), and DNA extraction using the illustra blood genomicPrep Mini Spin commercial kit (GE Healthcare, Little Chalfont, Buckinghamshire, UK). The aliquot without anticoagulant was used to measure serum ferritin by chemiluminescence (Immulite, Diagnostics Products Co., Los Angeles, CA, USA).

The mutations most commonly associated with the disease, viz., $\beta^{0}$ IVS-I-1 $(\mathrm{G} \rightarrow \mathrm{A}), \beta^{+}$IVS-I-6 $(\mathrm{T} \rightarrow \mathrm{C})$ and $\beta^{0} 39(\mathrm{C} \rightarrow \mathrm{T})$, were investigated by PCR-RFLP. PCR was carried out in a GeneAmp 9700 thermocycler (Applied Biosystems, Foster City, CA, USA), using the primers EA74 (5'-GGTTTGAAGTCCAACTCCT-3') and EA72 (5'-CACTCAGTGTGGCAAAGGTG-3') as described by Sirvent et al. (1998). The amplified products and digested samples were visualized by electrophoresis in $2 \%$ agarose gels followed by staining with ethidium bromide, the results then being recorded in a photodocumentation system (Sambrook et al., 1989). A previously sequenced standard sample for homozygosis and heterozygosis was used for each mutation investigated.

Complete beta-gene sequencing, from the $5^{\prime}$ promoter region to the 3' untranslated region (3' UTR), was undertaken when no mutation was otherwise identified by PCR-RFLP. Sequencing was with primers described by
Miranda et al. (1997), as well as the DYEnamic ET Dye Terminator Kit (GE Healthcare, Little Chalfont, Buckinghamshire, UK), and a MegaBace 1000 DNA Analysis System automatic sequencer (Molecular Dynamics, Amersham Pharmacia Biotech, Sunnyvale, CA, USA).

Descriptive analysis (mean and standard deviation), as well as the Student's t-test, Kolmogorov-Smirnov test, and Levene test were used for statistical analysis with SPSS for Windows version 10.0 and Microsoft Office Excel 2007. A significance level of $(p<0.05$ was used in all the tests.

Of the 35 patients included in the study, 31 were heterozygous and 4 homozygous for beta-thalassemia. Of the 31 heterozygotes, $13(41.9 \%)$ bore the $\beta^{+}$IVS-I-6 $(\mathrm{T} \rightarrow \mathrm{C})$ mutation and $15(48.4 \%)$ the $\beta^{0}$ IVS-I- $1(\mathrm{G} \rightarrow \mathrm{A})$ mutation, whereas in $3(9.7 \%)$ no mutation could be identified by PCR-RFLP. DNA from the latter three patients was submitted to beta-globin gene sequencing, thereby revealing two to be heterozygous for the $\beta^{+}$IVS-I-110 $(\mathrm{G} \rightarrow \mathrm{A})$ mutation and one for the $\beta^{+}$IVS-I-5 $(\mathrm{G} \rightarrow \mathrm{C})$ mutation. All the four homozygous patients bore the $\beta^{+}$IVS-I- $6(\mathrm{~T} \rightarrow \mathrm{C})$ mutation.

Of the 39 thalassemia alleles investigated, 53.8\% bore the IVS-I-6 mutation, $38.5 \%$ the IVS-I-1, 5.1\% the IVS-I- 110 , and $2.6 \%$ the IVS-I-5 mutation.

Comparison of hematological analysis between thalassemia patients without iron deficiency and heterozygous for $\beta^{+}$IVS-I-6 $(\mathrm{T} \rightarrow \mathrm{C})$ and $\beta^{0}$ IVS-I-1 $(\mathrm{G} \rightarrow \mathrm{A})$ mutations, revealed a significant difference as regards $\mathrm{MCV}$ $(\mathrm{p}=0.023), \mathrm{MCH}(\mathrm{p}=0.007)$, and $\mathrm{Hb} \mathrm{A}_{2}(\mathrm{p}<0.001)$ quantification. Nevertheless, the comparison of laboratory analyses between patients heterozygous and homozygous for the IVS-I-6 mutation, revealed a statistically significant difference $(\mathrm{p}<0.05)$ for all the parameters analyzed (Table 1).

Table 1 - Comparison of $\beta^{0}$ IVS-I-1 $(\mathrm{G} \rightarrow \mathrm{A})$ and $\beta^{+}$IVS-I-6 $(\mathrm{T} \rightarrow \mathrm{C})$ mutations found in this study with blood indices

\begin{tabular}{|c|c|c|c|c|c|}
\hline \multirow[t]{2}{*}{ Blood indices } & \multicolumn{5}{|c|}{ Type of mutation } \\
\hline & $\begin{array}{c}\text { Heterozygotes } \\
\beta^{0} \text { IVS-I-1 }(\mathrm{N}=12)^{*}\end{array}$ & $\begin{array}{c}\text { Homozygotes } \\
\beta^{+} \text {IVS-I-6 }(\mathrm{N}=4)\end{array}$ & $\begin{array}{c}\text { Heterozygotes } \\
\beta^{+} \text {IVS-I-6 }(\mathrm{N}=9)^{*}\end{array}$ & $\mathrm{p}$ value ${ }^{(1, \mathrm{a})}$ & $\mathrm{p}$ value $\mathrm{e}^{(1, \mathrm{~b})}$ \\
\hline Hemoglobin $(\mathrm{g} / \mathrm{dL})$ & $10.0 \pm 1.0$ & $7.8 \pm 0.8$ & $11.8 \pm 1.1$ & $<0.001$ & $<0.001$ \\
\hline Red blood cells $\left(\times 10^{12} / \mathrm{L}\right)$ & $5.21 \pm 0.71$ & $4.39 \pm 0.51$ & $5.47 \pm 0.31$ & 0.320 & 0.001 \\
\hline $\mathrm{MCV}(\mathrm{fL})$ & $63.3 \pm 3.8$ & $60.0 \pm 5.8$ & $68.0 \pm 4.5$ & 0.023 & 0.027 \\
\hline $\mathrm{MCH}(\mathrm{pg})$ & $19.3 \pm 1.7$ & $17.9 \pm 1.5$ & $21.7 \pm 2.0$ & 0.007 & 0.006 \\
\hline Hemoglobin A (\%) & $93.3 \pm 1.8$ & $83.4 \pm 5.0$ & $95.1 \pm 0.5$ & 0.009 & 0.018 \\
\hline Hemoglobin $\mathrm{A}_{2}(\%)$ & $5.3 \pm 0.6$ & $5.7 \pm 0.6$ & $4.1 \pm 0.2$ & $<0.001$ & 0.010 \\
\hline Hemoglobin F (\%) & $1.4 \pm 1.8$ & $10.9 \pm 5.2$ & $0.8 \pm 0.5$ & 0.333 & 0.029 \\
\hline
\end{tabular}

${ }^{(1)} \mathrm{p}$ value in the Student $\mathrm{t}$-test for independent samples.

(a) heterozygous for $\beta^{0}$ IVS-I- 1 and $\beta^{+}$IVS-I-6 mutations.

(b) heterozygous and homozygous for the $\beta^{+}$IVS-I-6 mutation.

*Seven patients (3 heterozygotes with the IVS-I-1 mutation and 4 with the IVS-I-6 mutation) with iron deficiency or whose serum ferritin levels had not been measured, were excluded. 
Orkin et al. (1982) identified the pattern of betathalassemia mutations in individuals of Mediterranean origin, wherein $\beta^{+}$IVS-I-110 $(\mathrm{G} \rightarrow \mathrm{A}), \beta^{0} 39(\mathrm{C} \rightarrow \mathrm{T}), \beta^{0}$ IVS-I-1 $(\mathrm{G} \rightarrow \mathrm{A})$, and $\beta^{+}$IVS-I-6 $(\mathrm{T} \rightarrow \mathrm{C})$ mutations were the most common. In Portugal, studies have shown that the most frequently found mutations are $\beta^{0} 39(\mathrm{C} \rightarrow \mathrm{T})$, IVS-I- $1(\mathrm{G} \rightarrow \mathrm{A})$ and IVS-I- $6(\mathrm{~T} \rightarrow \mathrm{C})$, with frequency varying in accordance with the region (Tamagnini et al., 1983; Cabeda et al., 1999; Faustino et al., 1999).

In Brazil, the pattern of beta-globin mutations varies according to the region. In the South and Southeast, the $\beta^{0} 39(\mathrm{C} \rightarrow \mathrm{T})$ and $\beta^{+}$IVS-I-110 $(\mathrm{G} \rightarrow \mathrm{A})$ mutations are very frequent (Martins et al., 1993; Bertuzzo et al., 1997; Fonseca et al., 1998; Reichert et al., 2008), whereas in the Northeast, the most frequent mutations are $\beta^{+}$IVS-I- $6(T \rightarrow C)$ and $\beta^{0}$ IVS-I-1 $(\mathrm{G} \rightarrow \mathrm{A})$ (Araújo et al., 2003).

This is the first study to determine the profile of beta-thalassemia mutations in the population of Rio Grande do Norte State. Through PCR/RFLP analysis, IVS-1-6 and IVS-1-1 mutations were detected in $36(92.3 \%)$ of the 39 thalassemia alleles analyzed. The remaining three $(7.7 \%)$ were characterized by beta-globin gene sequencing.

The Brazilian population is one of the most heterogeneous in the world, due to five centuries of interethnic crossing of peoples from three continents, namely, European colonizers, mainly represented by the Portuguese, African slaves and autochthonous Amerindians (Reichert et al., 2008). As regards European immigration, it is estimated that about 500,000 Portuguese arrived in the country between 1500 and 1808. Significantly, in the approximately 100-year-period from 1872 to 1975 , Brazil received ever increasing numbers of immigrants from various parts of the world, viz., Italians (34\%), Portuguese (29\%), Spanish (14\%), Japanese (5\%), Germans (4\%), Lebanese and Syrians (2\%), and others (12\%) (Pena et al., 2009). The population of Rio Grande do Norte is the result of miscegenation between Amerindians, sub-Saharan Africans, and European colonizers, the African influence having been insignificant. Of the Europeans, the Portuguese exerted the greatest influence, followed by the French. Although the Dutch were also present in the state, their contribution to the genetic makeup of the population was not significant (Cascudo, 1980).

The high frequency of IVS-I-6 (53.8\%) and IVS-I-1 (38.5\%) mutations appears to have resulted from the Portuguese contribution to the genetic makeup of the population of Rio Grande do Norte. Both these mutations were also frequent in Pernambuco, thereby demonstrating the thus far heterogeneity of beta-thalassemia in Brazil (Araújo et al., 2003).

In the present study, the IVS-I-110 $(\mathrm{G} \rightarrow \mathrm{A})$ mutation was identified in two out of the three patients whose $\beta$ genes were sequenced. In Brazil, this mutation was the most commonly found in the southern and southeastern re- gion (Martins et al., 1993; Bertuzzo et al., 1997; Reichert et al., 2008). The $\beta^{+}$IVS-I-5 $(\mathrm{G} \rightarrow \mathrm{C})$ mutation, found in the third patient, and which could not be characterized by PCR-RFLP, was also encountered, with a frequency of $9.3 \%$, in a population studied by Araújo et al. (2003). This mutation is very common in Southeast Asia, especially Malaysia and Indonesia, as well as in various regions of India (Thein, 1998).

PCR-RFLP, through its usefulness in identifying the most common beta-thalassemic alleles in the population studied, represents a practical alternative in situations where sequencing is unavailable. As there are no records to date of the types of beta-thalassemia mutations found in Rio Grande do Norte, and as studies have shown that the pattern of such mutations varies according to ethnic influence in the different regions of Brazil, the authors believe this study will play an important role in acquiring a greater understanding of the molecular profile of beta-thalassemia in Brazil.

\section{Acknowledgments}

Research was supported by the Conselho Nacional de Desenvolvimento Científico e Tecnológico (CNPq, Grant n. 409766/2006-2) and the Fundação de Amparo à Pesquisa do Estado de São Paulo (FAPESP, grant n. 2008/57441-0).

\section{References}

Araújo AS, Silva WA, Leão SAC, Bandeira FCGM, Petrou M, Modell MB and Zago MA (2003) A different molecular pattern of $\beta$-thalassemia mutations in northeast Brazil. Hemoglobin 27:211-217.

Bertuzzo CS, Sonati MF and Costa FF (1997) Hematological phenotype and the type of $\beta$-thalassemia mutation in Brazil. Braz J Genet 20:319-321.

Betke K, Marti NR and Schlicht I (1959) Estimation of small percentages of fetal haemoglobin. Nature 184:1877-1878.

Bezerra TMM (1984) Quantificação de hemoglobina $A_{2}$ por eletroforese em acetato de celulose. Rev Bras Patol Clin 20:143-145.

Cabeda JM, Correia C, Estevinho A, Simões C, Amorim ML, Pinho L and Justiça B (1999) Unexpected pattern of $\beta$-globin mutations in $\beta$-thalassaemia patients from northern Portugal. Br J Haematol 105:68-74.

Cascudo LC (1980) História da cidade do Natal. Civilização Brasileira, Rio de Janeiro, 470 pp.

Dacie JV and Lewis SM (1995) Practical Haematology. Churchill Livingstone, Edinburgh, $608 \mathrm{pp}$.

Faustino P, Pacheco P, Loureiro P, Nogueira PJ and Lavinha J (1999) The geographic pattern of $\beta$-thalassaemia mutations in the Portuguese population. Br J Haematol 107:903-904.

Fonseca SF, Kerbauy J, Escrivão C, Figueiredo MS, Cancado R, Arruda VR, Saad STO and Costa FF (1998) Genetic analysis of $\beta$-thalassemia major and $\beta$-thalassemia intermedia in Brazil. Hemoglobin 22:197-207.

Freitas EM and Rocha FJ (1983) Detection of beta-thalassemia heterozygotes among caucasians from Porto Alegre, RS, Brazil. Braz J Genet 6:185-188. 
Martins CSB, Ramalho AS, Sonati MF, Gonçalves MS and Costa FF (1993) Molecular characterization of beta thalassemia heterozygotes in Brazil. J Med Genet 30:797-798.

Miranda SRP, Fonseca SF, Figueiredo MS, Yamamoto M, Grotto HZW, Saad STO and Costa FF (1997) Hb Koln [a2b298(FG5) Val $\rightarrow$ Met] identified by DNA analysis in a Brazilian family. Braz J Genet 20:745-748.

Orkin SH, Kazazian Jr HH, Antonarakis SE, Goff SC and Boehm CD (1982) Linkage of $\beta$-thalassemia mutations and $\beta$-globin gene polymorphisms with DNA polymorphisms in human $\beta$-globin gene cluster. Nature 296:627-631.

Pena SDJ, Bastos-Rodrigues L, Pimenta JR and Bydlowski SP (2009) DNA tests probe the genomic ancestry of Brazilians. Braz J Med Biol Res 42:870-876.

Ramalho AS, Silva RBP, Teixeira RC and Compri MB (1999) Hemoglobin screening: Response of a Brazilian community to optional programs. Cad Saúde Pública 15:591-595.

Reichert VCD, Castro SM, Wagner SC, Albuquerque DM, Hutz MH and Leistner-Segal S (2008) Identification of $\beta$-thalassemia mutations in South Brazilians. Ann Hematol 87:381-384.
Sambrook J, Fritsch EF and Maniatis T (1989) Molecular Cloning: A Laboratory Manual. 2nd edition. Cold Spring Harbor Laboratory Press, New York, 1659 pp.

Sirvent MP, Miralles IM, Gilabert PB, Alejos EL, Rejas MAG, Montaña AV, Astigarraga AT, Carpio MAD, Silvestre MM, Espinosa ARL, et al. (1998) Molecular characterization of thalassaemias in the Valencia community and its relationship with the haematological phenotype. Sangre 43:392398.

Tamagnini GP, Lopes MC, Castanheira ME and Wainscoat JS (1983) $\beta^{+}$thalassaemia - Portuguese type: Clinical, haematological and molecular studies of a newly defined form of $\beta$ thalassaemia. Br J Haematol 54:189-200.

Thein SL (1998) $\beta$-thalassaemia. Baillieres Clin Haematol 11:91-126.

Weatherall DJ (2001) Phenotype-genotype relationships in monogenic disease: Lessons from the thalassaemias. Nat Rev Genet 2:245-255.

Associate Editor: Francisco Mauro Salzano

License information: This is an open-access article distributed under the terms of the Creative Commons Attribution License, which permits unrestricted use, distribution, and reproduction in any medium, provided the original work is properly cited. 